\title{
BRIEF
}

\section{Designing an Escape Room to Increase Pharmacy Preceptor Knowledge of the Pharmacists' Patient Care Process}

\author{
Lisa M. Richter, PharmD ${ }^{\mathrm{a}}$, Jeanne E. Frenzel, PharmD, $\mathrm{PhD}^{\mathrm{a}, \mathrm{b}}$ \\ ${ }^{a}$ North Dakota State University, College of Health Professions, Fargo, North Dakota \\ ${ }^{\mathrm{b}}$ Editorial Board Member, American Journal of Pharmaceutical Education, Arlington, Virginia \\ Submitted March 25, 2020; accepted July 14, 2020; published January 2021.
}

Objective. To design and assess the use of an escape room for pharmacy preceptor development.

Methods. An escape room for preceptor development that focused on the Pharmacists' Patient Care Process (PPCP), preceptor resources, and the school of pharmacy's mission and vision was created. Teams had to solve digital and practical puzzles to escape a pharmacy. The team to correctly solve all the puzzles the fastest was considered to have escaped the pharmacy. Escape room puzzles included digital locks, cipher wheels, a rebus puzzle, riddle, hidden object, and other puzzles. Preceptor's knowledge of the PPCP and perceptions of the game were evaluated using a pre- and post-activity test and survey.

Results. Fifteen preceptors with a variety of practice sites and precepting experience participated in a matched pre-and post-activity survey. Preceptor knowledge of the order of the PPCP improved, with nine $(60 \%)$ preceptors answering correctly before participating in the activity vs $13(87 \%)$ after. However, the preceptors were less likely to correctly answer the type of approach the PPCP uses after completing the escape room activity, with 14 (93\%) answering correctly before vs $10(67 \%)$ after. Participants' perceptions of the game were positive and all preceptors agreed or strongly agreed that they would recommend participating in this activity to another preceptor.

Conclusion. A preceptor development escape room was viewed positively by preceptors. Future research should focus on digital-only escape rooms for preceptors to increase availability and participation.

Keywords: preceptor development, escape room, gaming, Pharmacists' Patient Care Process (PPCP)

\section{INTRODUCTION}

Preceptors play an important role in the training and education of pharmacy students. They are uniquely positioned to help students synthesize and apply the Pharmacists' Patient Care Process (PPCP) from the didactic curriculum into practice. ${ }^{1,2}$ Preceptors who have engaged in preceptor development have been reported to be more confident in their ability to promote skills related to critical thinking and problem-solving. ${ }^{3}$ The Accreditation Council for Pharmacy Education (ACPE) standards and guidance document describe content for preceptor education but not format. ${ }^{4,5}$ Mulherin and colleagues published 12 recommendations for high-quality preceptor development programs, including a call that the "gamification of a learning platform should be trialed and researched as a viable means to increasing preceptor

Corresponding Author: Lisa M. Richter, North Dakota State University, College of Health Professions, Fargo, ND. Tel: 701-231-5178. Email: Lisa.Richter.1@ndsu.edu engagement and effectiveness in continuous professional preceptor development." 6

One popular gamification of learning is escape rooms. Participants in pharmacy-based educational escape room games have demonstrated increases in knowledge and improvement in clinical skills. ${ }^{7-9}$ In addition, participants perceive educational escape rooms to positively impact game player engagement, critical thinking, application of learned concepts, and teamwork. ${ }^{8,10-12}$ However, almost all pharmacy escape room literature is directed at educating student pharmacists..$^{7-13}$ The purpose of this study was to design a pharmacist preceptor development escape room game and to assess changes in knowledge and perception following participation in the game.

\section{METHODS}

Preceptor development at North Dakota State University (NDSU) included: live and recorded lectures presented by faculty members, access to online modules, 


\section{American Journal of Pharmaceutical Education 2021; 85 (1) Article 8073.}

newsletters, site visits and telephone calls, an annual teaching and research seminar, recorded presentations, an annual live event at a career fair, and programming at the annual state pharmacy convention. In 2019 faculty members in the NDSU School of Pharmacy created a live preceptor development escape room game to offer a unique, fast-paced, hands-on alternative for pharmacy preceptor development at off-campus events.

The preceptor development escape room was facilitated by two faculty members and piloted with approximately 15 student pharmacists prior to use with preceptors. Based on pilot results, adjustments were made to the delivery of the game specific to timing and workflow. For example, rather than have teams move between stations, facilitators brought the clues to the teams. This prevented bottlenecks at stations and allowed teams to continue game play without having to wait for other teams. Following the pilot, two separate one-hour preceptor development escape rooms were offered. One was facilitated at a district meeting of the North Dakota Pharmacists Association in 2019 and one for ACPE continuing education at the annual North Dakota pharmacy convention in 2019. The escape room was open to all meeting attendees including nonpreceptors.

The objectives of the escape room were for participants to use the preceptor handbook, locate and understand the school's mission and vision statement, and use the PPCP to problem solve effectively through the gamification of a patient case. ${ }^{2}$ Faculty created one digital escape room and one practical escape room consisting of five escape room-themed puzzles (Appendix 1). Prior to game play, participants received five minutes of instruction. Participants formed their own groups of up to eight people, similar to a non-pharmacy escape room. Groups were seated at round tables and required to have one electronic device per team. The electronic device was needed for the digital escape room. Participants had 45 minutes to escape both the digital and practical escape rooms. The game was followed by a 10-minute debriefing.

The gaming premise was as follows: on the first day of a new rotation, a preceptor attempted to open a door to admit a student, but the door locked before the student could enter the pharmacy. Teams were to solve digital and practical escape room puzzles to escape the pharmacy and meet their new student.

Teams started in the digital escape room. Using their electronic device, teams watched an 18-second video outlining digital game play. Participants then encountered a screen with images that were hyperlinked to the school's preceptor handbook, the PPCP wheel, and an image of the school of pharmacy building that was linked to the school's mission and vision statements. Google Forms
(Google, Menlo Park, CA), a survey administration software, was used to create two digital locks. Settings within a Google form were used to lock answers, preventing participants from advancing to the next activity until the correct answer was typed into the form. To solve the locks, participants had to correctly answer questions regarding preceptor responsibilities (puzzle 1) and the school's mission and vision statements (puzzle 2). If solved correctly, teams received a paper PPCP passport used to document their puzzle-solving progress during the practical escape room. Teams were to solve a puzzle related to each part of the PPCP. If solved correctly, the team advanced to a new puzzle and was awarded a PPCP sticker to add to their passport. Puzzles could be completed in any order, and multiple distractors were included with each puzzle.

To be awarded a PPCP "collect" sticker, teams had to collect a patient's medication-related allergy information from an electronic health record printout and successfully decode the allergy with a cipher wheel (puzzle 3). The electronic health record was created in SOAPware (Fayetteville, AR) using simulated patient information.

To be awarded a PPCP "assess" sticker, teams had to determine the organism a patient was infected with by solving a rebus puzzle. They then had to use the guidelines for skin and soft tissue infections provided to them to decode a susceptibility chart to determine an appropriate antibiotic to treat the patient (puzzle 4). ${ }^{14}$

To receive a PCPP "plan" sticker, teams had to choose an antibiotic therapy plan based on information in puzzle 4. Teams were given several therapy plans to consider, each of which was color-coded to match page numbers in a reference book. As part of puzzle 5, only the correct therapy plan color matched the numbers that were used to determine the provider's phone number needed to move on to the next puzzle.

To receive a PCPP "implement" sticker, for puzzle 6, teams scanned a Quick Response (QR) code and listened to a recorded patient's question. Investigators created the QR code using a free online QR code generator. In the recording, the patient asks for clarification of the goals of therapy for a specific inhaler. Participants were required to place an overlay over the patient's medication list to decode and view the list. The list revealed by the overlay was the original list found in the patient chart used for puzzle 1 . Inhaler-based therapy was chosen as the focus of the puzzle, as participants were encouraged to look at the whole patient and not just one disease state.

For puzzle 7, teams were asked to suggest a new antibiotic for the patient because of adverse effects the patient experienced after taking the first drug prescribed. To do this, teams had to complete a paper-based maze. 


\section{American Journal of Pharmaceutical Education 2021; 85 (1) Article 8073.}

The letters found in the correct path of the maze spelled out a riddle which, when solved, guided teams to a hidden object. Once the object was found, teams received a PPCP "follow-up" sticker.

If a puzzle was solved incorrectly, the team had to write and display a preceptor pearl. These were displayed during the game and collected after the game concluded. Additionally, if a team was having difficulty solving a puzzle, the team could write a preceptor pearl in exchange for one hint. The fastest team to solve all the puzzles was considered to have escaped the pharmacy and concluded the game for all teams. Faculty facilitated a debriefing after the game to reinforce key concepts.

Pre- and post-game surveys were administered electronically to participants via Qualtrics (Provo, UT). Demographic information collected included the preceptor's practice setting, years in practice, years serving as a preceptor, type of rotations precepted, and any previous experience with an escape room. Preceptors were also asked to answer six knowledge-based, multiplechoice questions. Four of the questions focused on the PPCP and two focused on the school's mission and vision and preceptor responsibilities. Preceptors also answered seven questions using a five-point Likert scale $(1=$ strongly disagree to $5=$ strongly agree). The questions related to the NDSU preceptor handbook, the PPCP, and the gaming activity format.

Perception and knowledge questions were analyzed using a paired $t$ test to determine whether participation in the escape room led to significant improvements in preceptors' knowledge of the PPCP (Table 2). An $\alpha$ level of .05 was set to determine statistical significance. The study was verified as exempt by the NDSU Institutional Review Board.

\section{RESULTS}

Eighteen pharmacists and pharmacy technicians participated in the preceptor development escape room. Participants were divided into two teams of four and two teams of five. Ten of the 18 participants were preceptors for the NDSU School of Pharmacy. An additional five preceptors completed the activity at the first session. Fifteen preceptors completed a matched pre-and postactivity survey $(R R=100 \%)$. Because of the focus of the project on preceptor development, only preceptor data were analyzed. Preceptor demographics are described in Table 1.

Participants believed that their ability to find and access the preceptor handbook, their familiarity with and ability to describe the PPCP, and their plans to use the PPCP increased significantly (Table 2). A paired sample $t$
Table 1. Demographics of Pharmacy Preceptors Who Participated in an Escape Room Focused on Knowledge of the Pharmacists' Patient Care Process $(n=15)$

\begin{tabular}{lc}
\hline & No. (\%) \\
\hline Practice setting & $8(53)$ \\
Community/retail pharmacy & $3(20)$ \\
Non-government hospital/health system & $2(13)$ \\
Ambulatory care & $1(7)$ \\
Government hospital/health system & $1(7)$ \\
Academic institution & \\
Years in practice & $2(13)$ \\
Less than 5 & $5(33)$ \\
5 years to less than 10 years & $2(13)$ \\
10 years to less than 15 years & $6(40)$ \\
15 or more years & $3(20)$ \\
Years as a preceptor & $6(40)$ \\
Less than 5 & $2(13)$ \\
5 years to less than 10 years & $4(27)$ \\
10 years to less than 15 years & \\
15 or more years & $1(7)$ \\
Preceptor for & $3(20)$ \\
IPPE & $11(73)$ \\
APPE & \\
Both APPE and IPPE & $10(67)$ \\
Have participated in an escape room (did not \\
have to be specific to pharmacy) in the past \\
Yes
\end{tabular}

Abbreviations: IPPE=Introductory Pharmacy Practice Experience, APPE $=$ Advanced Pharmacy Practice Experience

test found a significant increase in preceptor knowledge of the order of the PPCP, with nine $(60 \%)$ answering correctly before the activity vs $13(87 \%)$ after $(p<.05)$. Preceptors were less likely to correctly answer the type of approach the PPCP uses after completion of the escape room (14 [93\%] vs 10 [67\%], $p<.05$; Table 2$)$. Ten preceptors $(67 \%)$ had previously participated in an escape room, and all $15(100 \%)$ preceptors agreed or strongly agreed that they would recommend the preceptor development escape room to another preceptor. The majority of the participants indicated on the pre-intervention survey that they were open to learning in a gaming format and preferred assembling information from a variety of sources, and their responses to these items did not change significantly after participating in the escape room activity.

\section{DISCUSSION}

The focus of this study was the design of a preceptor development escape room and assessment of its effectiveness in increasing preceptors' knowledge of the PPCP. After participating in the game, participants' 


\section{American Journal of Pharmaceutical Education 2021; 85 (1) Article 8073.}

Table 2. Pharmacy Preceptors' Survey Responses Before and After Participating in an Escape Room Focused on the Pharmacists' Patient Care Process $(\mathrm{n}=15)$

\begin{tabular}{|c|c|c|c|}
\hline & Pre-intervention & Post-intervention & $p$ Value \\
\hline \multicolumn{4}{|l|}{ Perception questions, Mean Response (SD) ${ }^{\mathrm{a}}$} \\
\hline $\begin{array}{l}\text { I am familiar with where to access the NDSU } \\
\text { preceptor handbook }\end{array}$ & $3.4(1.3)$ & $4.6(0.5)$ & .006 \\
\hline I am familiar with the PPCP & $3.2(1.1)$ & $4.4(0.6)$ & .001 \\
\hline I can describe the importance of the PPCP & $3.3(1.0)$ & $4.3(0.5)$ & .003 \\
\hline $\begin{array}{l}\text { I currently use or plan to use the PPCP } \\
\text { with students on my rotation }\end{array}$ & $2.7(1.5)$ & $3.9(1.4)$ & .006 \\
\hline I am open to learning in a game format & $4.5(0.5)$ & $4.5(0.5)$ & .33 \\
\hline $\begin{array}{l}\text { I prefer assembling information from a } \\
\text { variety of sources when learning new } \\
\text { material }\end{array}$ & $4.3(0.7)$ & $4.4(0.6)$ & .43 \\
\hline $\begin{array}{l}\text { In general, I enjoy playing games (video } \\
\text { games, board games, social media games) }\end{array}$ & $3.9(0.8)$ & $4.3(0.7)$ & .02 \\
\hline
\end{tabular}

Knowledge questions, No. (\%) of participants

choosing this response ${ }^{\mathrm{b}}$

The PPCP should be used in these settings?

$11(73) \quad 12(80) \quad .16$

What is the correct order of the PPCP?

$9(60)$

$13(87)$

$10(67)$

.04

What type of approach does the PPCP use?

$14(93)$

$11(73)$

.04

Which is NOT part of the PPCP process?

$13(87)$

$15(100)$

.16

According to the NDSU SOP Mission and

$13(87)$

work with?

According to the NDSU SOP Preceptor

Handbook, preceptor responsibilities

$14(93)$

$14(93)$

include?

Abbreviations: PPCP=Pharmacists' Patient Care Process, NDSU SOP=North Dakota State University School of Pharmacy

${ }^{\text {a }}$ Responses based on a five-point Likert-scale: $1=$ strongly disagree, $2=$ disagree, $3=$ neutral, $4=$ agree, $5=$ strongly agree

${ }^{\mathrm{b}}$ Responses to multiple-choice questions.

${ }^{\mathrm{c}}$ Responses to a multiple-choice question on which participants were asked to select all that apply.

perceived abilities to find and access the preceptor handbook, familiarity with and abilities to describe the PPCP, and commitment to using the PPCP significantly increased. In addition, the preceptors' knowledge of the process of the PPCP significantly increased. The researchers encourage other schools to consider the gamification of preceptor development experiences to better engage preceptors and to meet accreditation expectations.

Publications describing pharmacy students changes in knowledge after completion of an escape room reported mixed results. ${ }^{7-9,11,13}$ This study was conducted with a diverse group of preceptors, and also produced mixed results in changes in knowledge. There are several explanations for this finding. Facilitators observed that participants did not contribute equally during game play, not all teams finished within the allotted time, and information needed to answer post-activity questions may have been missed because of the pace of the game. Finally, the post-activity survey was completed by participants as time was expiring which may have caused them to rush through the survey, resulting in decreased performance on some knowledge questions. Future offerings should allow additional time for game play, debriefing, and assessment.

The preceptor development escape room could be modified for use at other schools to increase awareness and use of the PPCP during introductory and advanced pharmacy practice experiences. The cost of conducting the escape room activity was minimal. The items in the escape room were reprinted after each use but otherwise did not require additional costs. However, the time required to conceptualize, develop, implement, and assess the escape room was significant up front (estimated 60 hours), but would likely be less if replicated by other institutions using our framework.

There are several limitations to this study. The study had a small sample size. The escape room was offered at the annual state pharmacy convention; however, another session was offered concurrently, which impacted the number of available participants. Many participants had no experience with escape rooms. This may have detracted them from wanting to try it for the first time in 


\section{American Journal of Pharmaceutical Education 2021; 85 (1) Article 8073.}

front of peers. Additionally, the escape room was offered as a live event. Previous literature found that $57 \%$ of pharmacy preceptors surveyed preferred electronic to live preceptor development. ${ }^{15}$ A completely digital escape room may be more appealing and accessible to a larger number of preceptors.

\section{CONCLUSION}

An innovative preceptor development escape room incorporating the PPCP was viewed positively by preceptors. Participation in the escape room resulted in increases in perceived abilities to use institution-specific preceptor tools, familiarity with and abilities to describe the PPCP, planned use of the PPCP, as well as increases in preceptor knowledge of the process of the PPCP. Future research should focus on developing digital-only escape rooms for preceptors to increase participation and availability.

\section{REFERENCES}

1. Haase KK, Crannage EF, Orlando PL, et al. Pharmacy practice faculty and preceptor development. JACCP J Am Coll Clin Pharm. 2020;3(3):696-712. doi:10.1002/jac5.1233.

2. Joint Commission of Pharmacy Practitioners. Pharmacists' Patient Care Process. May 29, 2014. https://jcpp.net/wp-content/uploads/ 2016/03/PatientCareProcess-with-supporting-organizations.pdf. Accessed December 20, 2020.

3. Assemi M, Corelli RL, Ambrose PJ. Development needs of volunteer pharmacy practice preceptors. Am J Pharm Educ. 2011; 75(1): 10. doi:10.5688/ajpe75110.

4. Accreditation Council for Pharmacy Education. Accreditation Standards and Key Elements for the Professional Program in Pharmacy Leading to the Doctor of Pharmacy Degree ("Standards 2016"). Published February 2015. https://www.acpe-accredit.org/pdf/ Standards2016FINAL.pdf. Accessed December 20, 2020.

5. Accreditation Council for Pharmacy Education. Guidance for the Accreditation Standards and Key Elements for the Professional Program in Pharmacy Leading to the Doctor of Pharmacy Degree
("Guidance for Standards 2016"). Published February 2015. https:// www.acpe-accredit.org/pdf/GuidanceforStandards2016FINAL.pdf. Accessed December 20, 2020.

6. Mulherin K, Walter S, Cox CD. National preceptor development program (PDP): influential evidence and theory. the first of a 3-part series. Curr Pharm Teach Learn. 2018;10(3):255-266. doi:10.1016/ j.cptl.2017.12.002.

7. Eukel HN, Frenzel JE, Cernusca D. Educational gaming for pharmacy students - design and evaluation of a diabetes-themed escape room. Am J Pharm Educ. 2017;81(7):6265. doi:10.5688/ajpe8176265.

8. Clauson A, Hahn L, Frame T, et al. An innovative escape room activity to assess student readiness for advanced pharmacy practice experiences (APPEs). Curr Pharm Teach Learn. 2019;11(7): 723-728. doi:10.1016/j.cptl.2019.03.011.

9. Kavanaugh R, George S, Lamberton N, Frenzel JE, Cernusca D, Eukel HN. Transferability of a diabetes escape room into an accelerated pharmacy program. Curr Pharm Teach Learn. 2020; 12(6):709-715. doi:10.1016/j.cpt1.2020.01.022.

10. Gordon SK, Trovinger S, DeLellis T. Escape from the usual: development and implementation of an 'escape room' activity to assess team dynamics. Curr Pharm Teach Learn. 2019;11(8): 818-824. doi:10.1016/j.cptl.2019.04.013.

11. Caldas LM, Eukel HN, Matulewicz AT, Fernández EV, Donohoe KL. Applying educational gaming success to a nonsterile compounding escape room. Curr Pharm Teach Learn. 2019;11(10): 1049-1054. doi:10.1016/j.cpt1.2019.06.012.

12. Cain J. Exploratory implementation of a blended format escape room in a large enrollment pharmacy management class. Curr Pharm Teach Learn. 2019;11(1):44-50. doi:10.1016/j.cpt1.2018.09.010. 13. Nybo SE, Klepser SA, Klepser M. Design of a disaster preparedness escape room for first and second-year pharmacy students. Curr Pharm Teach Learn. 2020;12(6):716-723. doi: 10.1016/j.cptl.2020.01.037.

14. Stevens DL, Bisno AL, Chambers HF, et al. Practice guidelines for the diagnosis and management of skin and soft tissue infections: 2014 update by the Infectious Diseases Society of America. Clin Infect Dis. 2014;59(2):e10-e52. doi:10.1093/cid/ciu296.

15. Davison M, Medina MS, Ray NE. Preceptor preferences for participating in electronic preceptor development. Pharm Pract (Granada). 2009;7(1):47-53. doi:10.4321/S1886-

36552009000100007. 
American Journal of Pharmaceutical Education 2021; 85 (1) Article 8073.

Appendix 1. Puzzles Used in a Preceptor Development Escape Room Intended to Increase Participants' Knowledge of the Pharmacists' Patient Care Process

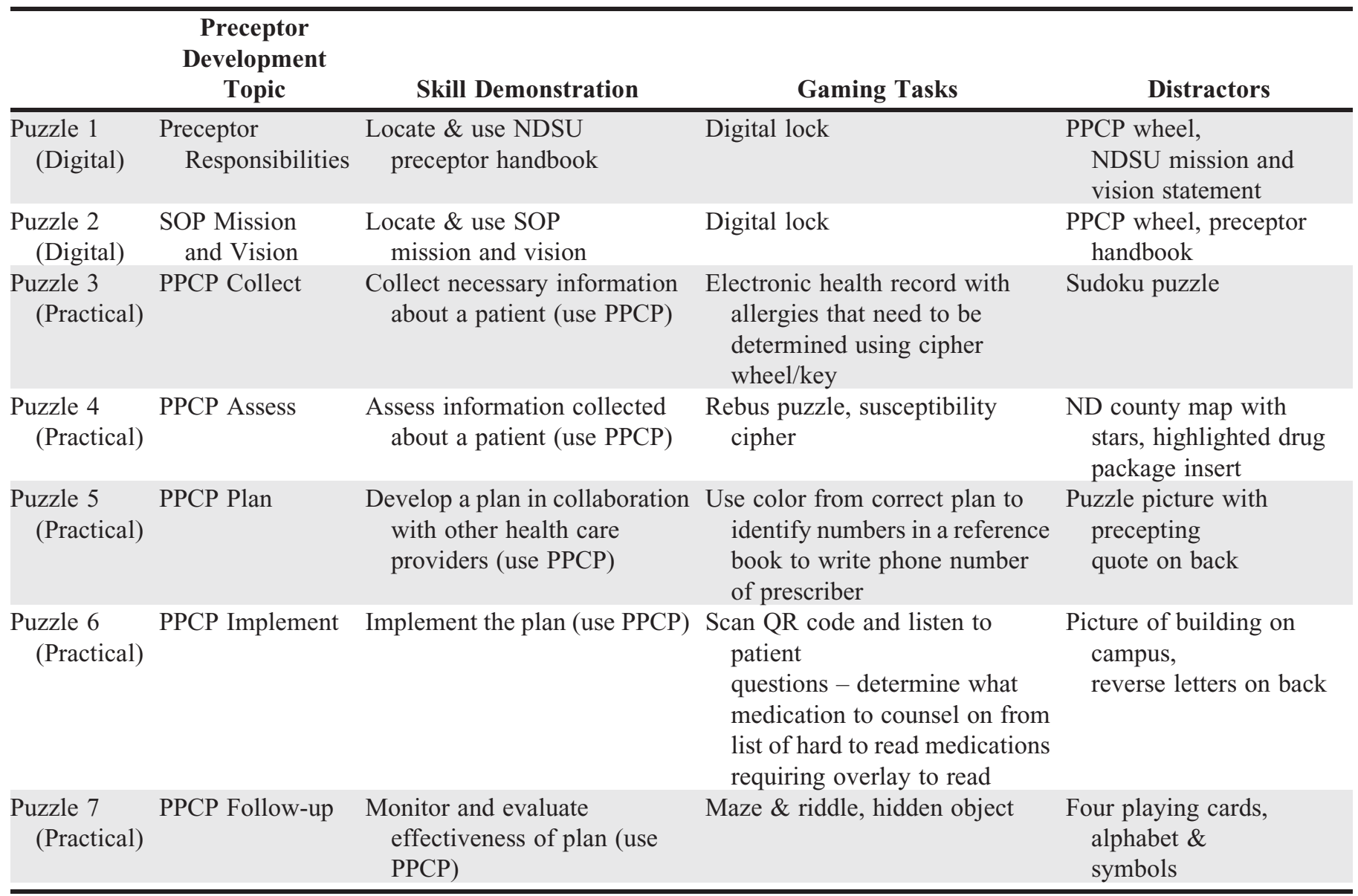

Abbreviations: $\mathrm{SOP}=$ School of Pharmacy, ND=North Dakota, NDSU = North Dakota State University, $\mathrm{QR}=$ quick response, $\mathrm{PPCP}=\mathrm{Pharma}-$ cists' Patient Care Process 